\title{
Characterization of Graphite Inclusions in Cast Iron by Cathodoluminescence and X-Ray Microanalysis.
}

\author{
Scott A. Wight ${ }^{1}$ and Jay R. Hitchings ${ }^{2}$ \\ ${ }^{1}$ Materials Measurement Science Division, National Institute of Standards and Technology, 100 Bureau \\ Drive, Gaithersburg, MD, 20899-8371,USA; <scott.wight@nist.gov>. \\ ${ }^{2}$ Comanche Technologies, 1393 Piedmont Drive, Downingtown, PA 19335, USA.
}

Cast iron describes a broad range of iron-carbon cast alloy that can contain a number of other elements as well. It can be made from re-melting pig iron, scrap metal and other intentional additions. Cast iron is differentiated from steel by the distinction that it contains at least $2.03 \%$ carbon [1]. Chemical composition, presence of nuclei, and cooling rate help determine the size, shape, and number of graphite inclusions in the cast iron. Materials are added to the melt or the pour to help achieve more desirable results. Further study is needed to better understand the formation and growth of these graphitic inclusions. A method for the rapid identification of graphitic inclusion nuclei and subsequent analysis is described.

Specimen preparation involves very careful metallographic grinding and polishing steps with fresh grit and papers and gentle cleaning between steps. The relatively soft graphite inclusions can be plucked out of the cast iron by too aggressive grinding and polishing (Figure 1A). Chemical etching [1], argon ion etching [2], and oxygen plasma etching [3] have been used as the final step to reveal the graphite inclusion. In this work, the specimens were potted in epoxy, and mechanically polished down to $3 \mu \mathrm{m}$ diamond. Some specimens were further finished with colloidal silica. This preparation creates a highly polished planar cross section through the graphite inclusions but it takes tedious searching to find an inclusion that happens to be exactly cross-sectioned through the intact nucleus (Figure 1B). Radiofrequency oxygen plasma etching of the cast iron cross-section attacks the graphite preferentially and exposes the nucleus just below the surface of the graphite. Too much etching will also liberate the nucleus, so some experimentation is necessary to find the proper etch time.

Cathodoluminescence (CL) imaging in the scanning electron microscope is demonstrated as a simple and rapid method to scan the surface of the oxygen plasma etched cast iron cross-section for exposed nuclei. Figure $2 \mathrm{~A}$ is an example of a graphite inclusion that has dislocations in the graphite growth where iron fingers extend from the surrounding metal into the inclusion. The x-ray map overlay in Figure 2B represents iron in red, carbon in blue, magnesium in yellow, silicon in green and aluminum in purple. The CL panchromatic color overlay in Figure $2 \mathrm{C}$ correlate the CL active nucleus with the magnesium, aluminum, and silicon rich areas in the x-ray map. Figure 3A represents another common inclusion type. The panchromatic CL overlay (Figure 3C) reveals several particles that correspond to silicon (red), magnesium (yellow), aluminum (purple), and calcium (aqua) in the x-ray map data in Figure 3B. Together the techniques can provide insight into the mechanism of graphite inclusion growth.

\section{References:}

[1] F J.M. Radzikowski in "ASM Handbook, Volume 9: Metallography and Microstructures", ed. G. VanderVort, (ASM International) p. 565.

[2] H. Nake and Y. Igarashi, Materials Transactions, 43 (2002) p. 2826.

[3] M.J. Lalich and J.R. Hitchings, AFS Transactions, 76-120 (1976) p. 653. 

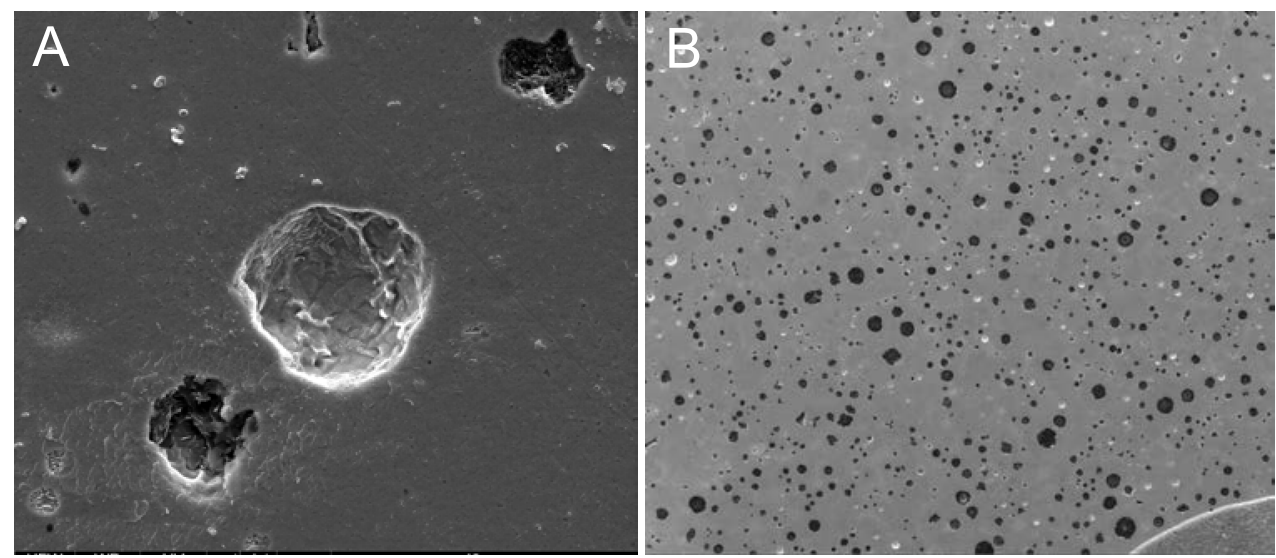

Figure 1. A) Secondary electron image of a cavity missing it's graphite inclusion, HFW is $84.6 \mu \mathrm{m}$; B) Low magnification secondary electron image of the polished cast iron cross-section to demonstrate the number and distribution of graphite inclusions, HFW is $1.81 \mathrm{~mm}$.

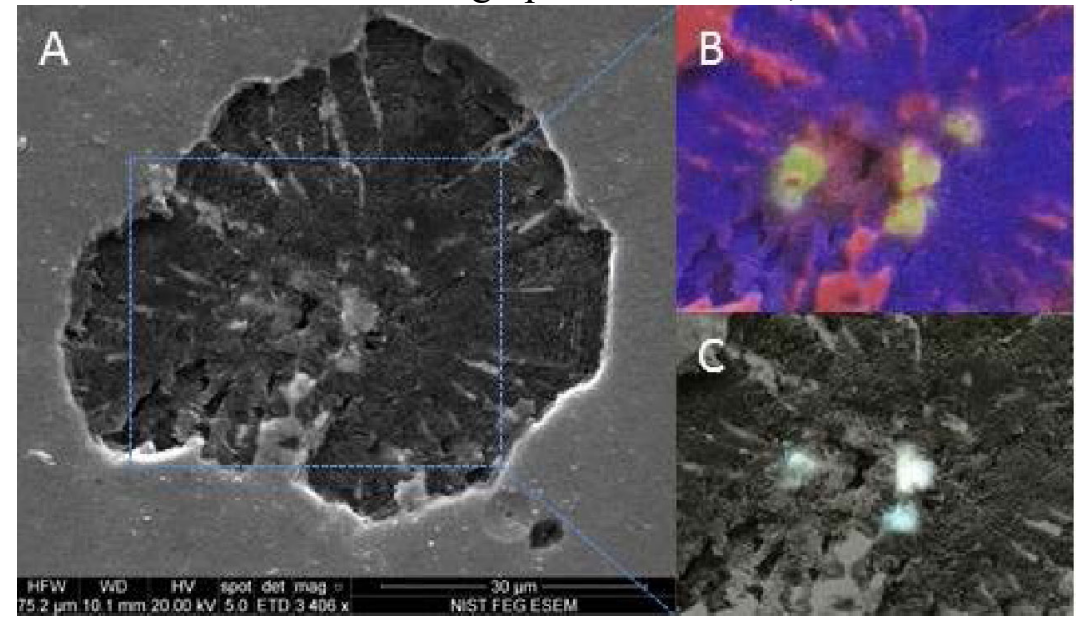

Figure 2. A) Secondary electron image of a graphite inclusion in cast iron, HFW is $75.2 \mu \mathrm{m}$; B) $\mathrm{X}$-Ray map data overlay (Fe, $\mathrm{C}, \mathrm{Mg}, \mathrm{Si}, \mathrm{Al}$ ) corresponding to the blue rectangle in $\mathrm{A}, \mathrm{HFW}$ is $9 \mu \mathrm{m}$; $\mathrm{C}$ ) $\mathrm{CL}$ panchromatic color image overlaid on SE image, HFW is $9 \mu \mathrm{m}$.

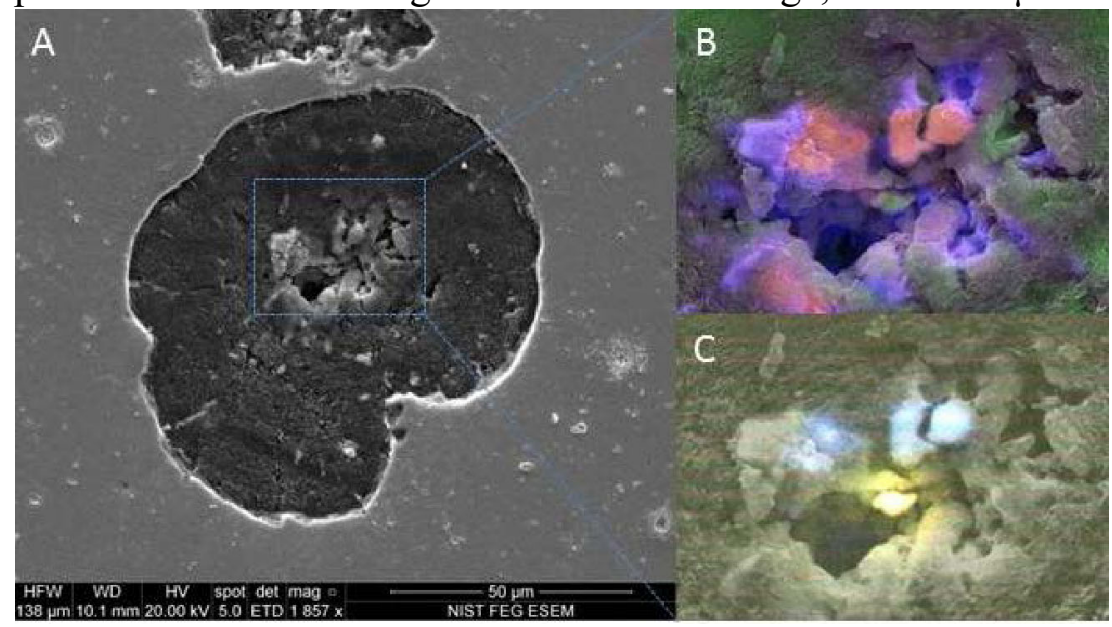

Figure 3. A) Secondary electron image of a graphite inclusion in cast iron, HFW is $138 \mu \mathrm{m}$; B) $\mathrm{X}$-Ray map data overlay (Fe, C, Si, Mg, Al, Ca) corresponding to the blue rectangle in A, HFW is $38 \mu \mathrm{m}$; C) CL panchromatic color image overlaid on SE image, HFW is $38 \mu \mathrm{m}$. 